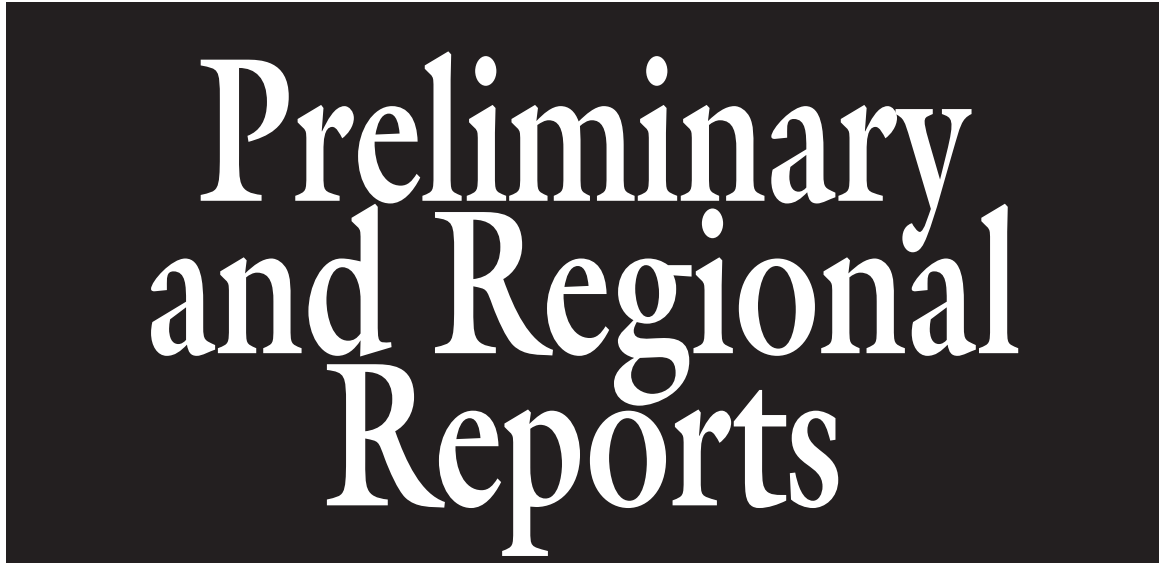

\title{
Staminate Flower Production and Fusarium Wilt Reaction of Diploid Cultivars Used as Pollenizers for Triploid Watermelon
}

\author{
Chris Gunter ${ }^{1,3,5}$ and Daniel S. Egel ${ }^{2,4}$
}

\begin{abstract}
Additional INDEX words. Citrullus lanatus, Fusarium oxysporum f. sp. niveum, nonharvested, pollination, host resistance

SUMMARY. Several cultivars of nonharvested watermelon (Citrullus lanatus) pollenizers were compared for staminate flower production in field tests and disease reaction to fusarium wilt [Fusarium oxysporum f. sp. Niveum (FON)] in both greenhouse and field tests. Differences were observed in staminate flower counts and fusarium wilt reactions in both years of field evaluations and to fusarium wilt among cultivars evaluated in the greenhouse. 'SP-1', 'Sidekick', and '5WDL 6146' were the cultivars with high staminate flower counts in the field both years. These cultivars also were among the most resistant to fusarium wilt in both years of field tests. Significant correlations occurred between the rankings of the cultivar's fusarium wilt reactions in both the two field and three greenhouse experiments, indicating a high degree of correlation between field and greenhouse tests.
\end{abstract}

$\mathrm{T}$ Triploid (seedless) watermelon production requires the use of diploid (seeded) cultivars to ensure pollination (Dittmar et al., 2010; Fiacchino and Walters, 2003; Maynard and Elmstrom, 1992; Rhodes et al., 1997). This is accomplished by planting a diploid watermelon cultivar in the field with the triploid watermelon plants. These pollenizer plants can be planted in a number of patterns including dedicated rows adjacent to the

\footnotetext{
The authors thank Sara Hoke and Chelsey Cardinal for technical assistance.

${ }^{1}$ Department of Horticultural Science, 230 Kilgore Hall, Box 7609, North Carolina State University, Raleigh, NC 27695-7609

${ }^{2}$ Department of Botany and Plant Pathology, 4369 North Purdue Road, Purdue University, Vincennes, IN 47591

${ }^{3}$ Vegetable Production Specialist

${ }^{4}$ Extension Plant Pathologist

${ }^{5}$ Corresponding author. E-mail: chris_gunter@ncsu.
} edu.

seedless rows or interplanting them within the rows with the seedless plants at various rates (Dittmar et al., 2010; Fiacchino and Walters, 2003; Maynard and Elmstrom, 1992; Rhodes et al., 1997). The typical ratio of pollenizer plants to the seedless plants ranges from 1:2 to 1:4 pollenizer:seedless plants (Dittmar et al., 2010; Fiacchino and Walters, 2003; Nesmith and Duval, 2001; Rhodes et al., 1997). Regardless of the planting arrangement or the ratio of diploid (seeded) plants to the seedless plants in a given area, a proportion of the total population of watermelon plants per acre must be dedicated to the pollenizer plants to ensure growth and development of both staminate flowers and fruit of diploid plants (Dittmar et al., 2009). Growers can market acceptable seeded watermelon; however, demand for these fruit continues to decline in proportion to that of seedless fruit (Lucier and Lin, 2001). Seeded fruit typically bring lower prices than the more desirable seedless fruit (U.S. Department of Agriculture, 2003), and the presence of the diploid cultivars used as the pollenizer plants restricts the number of more valuable triploids that can be planted.

Therefore, many growers interplant older diploid cultivars, which have lower seed prices, within the seedless rows. The purpose of this system is to plant the entire acreage with seedless plants at normal production spacing and interplant pollenizer plants without regard to their fruit production and value. Seed companies have responded to this demand by developing pollenizer cultivars that produce inferior fruit quality (e.g., unacceptably small fruit or soft rinds) and unique growth habits or flowering characteristics. These newer pollenizer culitvars, because of their compact growth habit, also offer less competition with triploid cultivars than the traditional diploid culitvars used as pollenizers.

The use of these newly developed pollenizers is relatively recent. Characteristics important for these exclusive pollenizers are staminate flower production and disease resistance. Previous works have shown that flowering characteristics of these pollenizers varies considerably (Dittmar et al., 2009, 2010; Fiacchino and Walters, 2003; Freeman and Olson, 2007; Maynard and Elmstrom, 1992; Rhodes et al., 1997). The production of sufficient staminate flowers that are easily accessible to bees at the same time as

\begin{tabular}{llll}
\hline $\begin{array}{l}\text { Units } \\
\text { To convert U.S. to SI, } \\
\text { multiply by }\end{array}$ & U.S. unit & SI unit & $\begin{array}{l}\text { To convert SI to U.S., } \\
\text { multiply by }\end{array}$ \\
\hline 29.5735 & $\mathrm{fl} \mathrm{oz}$ & $\mathrm{mL}$ & 0.0338 \\
0.3048 & $\mathrm{ft}$ & $\mathrm{m}$ & 3.2808 \\
0.0929 & $\mathrm{ft}^{2}$ & $\mathrm{~m}^{2}$ & 10.7639 \\
3.7854 & gal & $\mathrm{L}$ & 0.2642 \\
2.54 & inch(es) & $\mathrm{cm}$ & 0.3937 \\
25.4 & inch $(\mathrm{es})$ & $\mathrm{mm}$ & 0.0394 \\
0.0254 & mil & $\mathrm{mm}$ & 39.3701 \\
$\left({ }^{\circ} \mathrm{F}-32\right) \div 1.8$ & ${ }^{\circ} \mathrm{F}$ & ${ }^{\circ} \mathrm{C}$ & $\left({ }^{\circ} \mathrm{C} \times 1.8\right)+32$
\end{tabular}


seedless pistillate flower production is critical to successful fruiting. Research has shown that daily staminate flower production is highly variable among cultivars (Dittmar et al., 2010; Fiacchino and Walters, 2003; Freeman and Olson, 2007; Maynard and Elmstrom, 1992; Rhodes et al., 1997; Stanghellini and Schultheis, 2005; Stanghellini et al., 1998).

We also have observed significant variability in the susceptibility of these dedicated pollenizers to fusarium wilt, caused by the soilborne fungus FON, in commercial fields. Pollenizers susceptible to fusarium wilt appear to produce fewer staminate flowers making them less effective as pollenizers. We have observed that watermelon plants often exhibit symptoms of fusarium wilt within 3 to 4 weeks of transplanting (Kleczewski and Egel, 2011), considerably before flowers are produced. While studies ranking the susceptibility of watermelon hybrids to fusarium wilt are available (Elmstrom and Hopkins, 1981; Martyn and McLaughlin, 1983; Zhang et al., 1995; Zhou and Everts, 2004), the relative host resistance rankings of these specialized diploids is not known. Management of fusarium wilt is difficult without good genetic resistance. For example, many triploid hybrids lack adequate host resistance (Egel and Hoke, 2007). The usefulness of crop rotations is limited because chlamydospores of FON may survive many years in the soil. Additionally, soil fumigation is considered too expensive to be useful to most watermelon producers (Egel and Martyn, 2007); thus, host resistance is the most economically useful strategy for management of fusarium wilt of watermelon.

The purpose of this study was to compare staminate flower production of dedicated pollenizers in a commercial watermelon field and evaluate the host resistance of dedicated pollenizers to fusarium wilt in the field as well as in a greenhouse inoculation study.

\section{Materials and methods}

The watermelon cultivars used in this study along with the seed company of origin and horticultural uses are listed in Table 1 . In addition to the diploids used as pollenizers, seeded cultivars traditionally grown for fresh market production and triploid cultivars also were included for comparison purposes. 'Black Diamond', not normally

Table 1. A list of watermelon cultivars, their seed company of origin, and horticultural use in the 2006 and 2007 field trials.

\begin{tabular}{|c|c|c|}
\hline Cultivar & Seed company ${ }^{z}$ & Horticultural use \\
\hline ACX 9825 & Abbott and Cobb & Nonharvested pollenizer \\
\hline Side Kick & Harris Moran & Nonharvested pollenizer \\
\hline Jenny & Nunhems & Nonharvested pollenizer \\
\hline Polimax 6017 & Nunhems & Nonharvested pollenizer \\
\hline Ace & Sakata Seed America & Nonharvested pollenizer \\
\hline Companion & Seminis Vegetable Seed & Nonharvested pollenizer \\
\hline Pinnacle & Southwestern Seed & Nonharvested pollenizer \\
\hline 5WDL 6132 & Syngenta & Nonharvested pollenizer \\
\hline 5WDL 6146 & Syngenta & Nonharvested pollenizer \\
\hline 5WDL 6148 & Syngenta & Nonharvested pollenizer \\
\hline SP-1 & Syngenta & Nonharvested pollenizer \\
\hline Mickey Lee & Willhite Seed & $\begin{array}{l}\text { Used as a nonharvested } \\
\text { pollenizer and diploid } \\
\text { cultivar }\end{array}$ \\
\hline Dixie Lee & Reimer Seeds & Diploid cultivar \\
\hline Regency & Seminis Vegetable Seed & Diploid cultivar \\
\hline Royal Sweet & Seminis Vegetable Seed & Diploid cultivar \\
\hline Allsweet & Willhite Seed & Diploid cultivar \\
\hline Black Diamond & Willhite Seed & Diploid cultivar \\
\hline Calhoun Gray & Willhite Seed & Diploid cultivar \\
\hline Charleston Gray & Willhite Seed & Diploid cultivar \\
\hline Crimson Sweet & Willhite Seed & Diploid cultivar \\
\hline Tri-X 212 & Rogers & Triploid cultivar \\
\hline Tri-X Triple Threat & Rogers & Triploid cultivar \\
\hline SSC 2220 & Shamrock Seed & Triploid cultivar \\
\hline SSC 2221 & Shamrock Seed & Triploid cultivar \\
\hline SW 4806 & Southwestern Seed & Triploid cultivar \\
\hline
\end{tabular}

${ }^{z}$ Abbott and Cobb (Jesup, GA), Harris Moran (Modesto, CA), Nunhems (Parma, ID), Sakata Seed America (Morgan Hill, CA), Seminis Vegetable Seed (Morgan Hill, CA), Southwestern Seed (Casa Grande, AZ), Syngenta (Wilmington, DE), Willhite Seed (Pollville, TX), Reimer Seeds (Mount Holly, NC), Rogers (Wilmington, DE), Shamrock Seed (Salinas, CA).

used as a pollenizer, was included because it is known to be susceptible to fusarium wilt (Martyn, 1987; Martyn and McLaughlin, 1983).

FUSARIUM WILT GREENHOUSE TRIALS. Greenhouse experiments were conducted at the Southwest Purdue Agricultural Center in Vincennes, IN Six seeds were planted per pot $\approx 1$ inch deep in 0.5 -gal polystyrene pots filled with a 4:1:1 mixture (v:v:v) of sand:peat:vermiculite mixture [sand (Quickrete Play Sand; Quickrete, Atlanta, GA), peat (Sphagnum Peat; Premier Horticulture, Quakertown, PA), vermiculite (Horticultural Vermiculite; Therm-O-Rock, New Eagle, PA)]. Seedlings were thinned to three per pot $\approx 10 \mathrm{~d}$ after sowing. Temperatures in the greenhouse ranged from 18 to $32{ }^{\circ} \mathrm{C}$.

Seedlings were inoculated with FON at the two true-leaf stage. Inoculum of FON was started on potato dextrose agar (PDA) medium (Difco, Sparks, MD). Four to five plugs (6-mm diameter) were cut from the margin of FON colonies on PDA plates and added to $100 \mathrm{~mL}$ of a sterile mineral salts medium (Esposito and Fletcher, 1961). The flasks were shaken (140 rpm) at $22{ }^{\circ} \mathrm{C}$ for $72 \mathrm{~h}$ to produce the inoculum that was composed primarily of microconidia. The medium was filtered through six layers of sterile cheesecloth to remove mycelia. The concentration was adjusted to $1 \times 10^{5}$ microconidia/mL with the aid of a hemacytometer. For inoculation, $100 \mathrm{~mL}$ of this solution was poured onto the surface of the soilless medium of pots containing three watermelon seedlings. The FON strain used in the greenhouse trials, designated $03-15$, is a race 1 strain isolated in 2003 from a diploid watermelon seedling used as a pollenizer for triploid watermelon production (Egel et al., 2005).

The watermelon seedlings were rated about every $2 \mathrm{~d}$ for disease severity using the Horsfall-Barratt rating scale (Horsfall and Barratt, 1945) beginning at the onset of wilt symptoms, $\approx 7 \mathrm{~d}$ postinoculation. The area under the disease progress curve (AUDPC) was determined by trapezoidal integration 
(Shaner and Finney, 1977). Each treatment was replicated three times in a completely randomized design on a greenhouse bench.

Field TRIALs. Field plots were established in a commercial watermelon field north of Vincennes, IN, that had a history of fusarium wilt. Each plot consisted of 10 plants spaced 30 inches between plants and on 5-ft centers. Rows were mulched with black plastic (24 inches wide, 2 mil, Visqueen 4020; Rideout Plastics Co., San Diego, CA). Experiments were laid out in a randomized complete block design with six replications per cultivar. In 2006, 19 cultivars were evaluated and in 2007, 18 cultivars were evaluated (Table 2 ).

Watermelon seedlings at the two true-leaf stage were transplanted by hand to the field on 23 May in 2006 and 14 May in 2007. Wilt ratings were conducted in 2006 on 17 and 23 June, and $5,10,17$, and 25 July. In 2007 , disease ratings were conducted on 1,7 , 14,21 , and 27 June. The AUDPC was determined by trapezoidal integration. Statistical analysis of differences between cultivars in the greenhouse and field trials was determined by analysis of variance using general linear models procedure and Fisher's least significant differences test for mean separation (SAS version 9.1; SAS Institute, Cary, NC). The wilt rankings of cultivars in the field and greenhouse trials were compared by including only those cultivars that appeared in each possible paired trial by simple regression (SAS version 9.1). Each cultivar was given a numerical ranking from the most susceptible cultivar to the most resistant based on AUDPC. The coefficient of correlation and the probability value are presented for all possible comparisons (Table 3). Recommended fertilization and pest control practices were used (Egel et al., 2006). Plots were not irrigated.

Staminate Flower Data. On a weekly basis, beginning 2 weeks after transplanting, open staminate flowers were quantified between 0800 and $1100 \mathrm{HR}$ on plants from two randomly selected $15-\mathrm{ft}^{2}$ areas of each plot on the dates indicated below. Each $15-\mathrm{ft}^{2}$ area encompassed about two pollenizer plants depending on where the random area occurred. These data were used to calculate the mean number of staminate flowers produced per square meter for each cultivar. In 2006, flowers were counted on 6, 13, 20, and 27 June and

Table 2. Comparison of diploid watermelon cultivars used as pollenizers for triploid watermelons for their susceptibility to fusarium wilt in the 2006 and 2007 field trials.

\begin{tabular}{lcc}
\hline Cultivar $^{\mathrm{z}}$ & 2006 AUDPC $\mathrm{AU}^{\mathrm{y}} \mathbf{x}$ & $2007 \mathrm{AUDPC}^{\mathbf{w}}$ \\
\hline Ace & $\mathrm{n} / \mathrm{t}^{\mathrm{v}}$ & $1,202.8 \mathrm{a}^{\mathrm{u}}$ \\
ACX 9825 & $142.4 \mathrm{~b}$ & $851.2 \mathrm{~b}$ \\
Allsweet & $22.9 \mathrm{c}$ & $70.8 \mathrm{hi}$ \\
Black Diamond & $278.4 \mathrm{a}$ & $1,148.7 \mathrm{a}$ \\
Calhoun Gray & $14.9 \mathrm{c}$ & $\mathrm{n} / \mathrm{t}$ \\
Charleston Gray & $18.0 \mathrm{c}$ & $\mathrm{n} / \mathrm{t}$ \\
Companion & $18.6 \mathrm{c}$ & $172.2 \mathrm{ghi}$ \\
Crimson Sweet & $19.2 \mathrm{c}$ & $\mathrm{n} / \mathrm{t}$ \\
Dixie Lee & $16.9 \mathrm{c}$ & $83.8 \mathrm{hi}$ \\
Jenny & $49.0 \mathrm{c}$ & $329.4 \mathrm{defgh}$ \\
Mickey Lee & $30.0 \mathrm{c}$ & $457.2 \mathrm{cdefg}$ \\
Pinnacle & $280.9 \mathrm{a}$ & $645.2 \mathrm{bc}$ \\
Polimax 6017 & $72.8 \mathrm{bc}$ & $542.4 \mathrm{cde}$ \\
Royal Sweet & $15.9 \mathrm{c}$ & $20.5 \mathrm{i}$ \\
Sidekick & $32.7 \mathrm{c}$ & $170.1 \mathrm{ghi}$ \\
SP-1 & $40.4 \mathrm{c}$ & $214.6 \mathrm{fghi}$ \\
SSC 2220 & $\mathrm{n} / \mathrm{t}$ & $488.3 \mathrm{cdef}$ \\
SSC 2221 & $\mathrm{n} / \mathrm{t}$ & $574.6 \mathrm{bcd}$ \\
SW 4806 & $28.9 \mathrm{c}$ & $\mathrm{n} / \mathrm{t}$ \\
Tri-X Triple Threat & $\mathrm{n} / \mathrm{t}$ & $272.0 \mathrm{efghi}$ \\
Tri-X 212 & $\mathrm{n} / \mathrm{t}$ & $169.9 \mathrm{ghi}$ \\
5WDL 6132 & $22.7 \mathrm{c}$ & $\mathrm{n} / \mathrm{t}$ \\
5WDL 6146 & $28.1 \mathrm{c}$ & $24.1 \mathrm{i}$ \\
5WDL 6148 & $15.4 \mathrm{c}$ & $\mathrm{n} / \mathrm{t}$ \\
$P$ value & 0.001 & 0.001 \\
\hline
\end{tabular}

${ }^{2}$ There were six replications of each row of 10 plants in a randomized complete block design.

'The area under the disease progress curve (AUDPC) was calculated from the Horsfall-Barratt ratings using trapezoidal integration (Shaner and Finney, 1977).

${ }^{x}$ Each plot was rated visually for severity 17 and 23 June and 5, 10, 17, and 25 July with the Horsfall-Barratt rating scale (Horsfall and Barratt, 1945).

wEach plot was rated visually for severity $1,7,14,21$, and 27 June.

"The cultivar was not tested for that particular year.

"Means within each column with a letter in common are not significantly different via Fisher's protected least significant difference test at $P=0.05$.

Table 3. Coefficient of correlation between numerical rankings of watermelon cultivars in field or greenhouse trials according to fusarium wilt of watermelon susceptibility trials. The trials were conducted in a commercial watermelon field in May 2006 and 2007 and in a greenhouse in Sept. and Nov. 2007 and Feb. 2008. The probability value of each simple regression is listed parenthetically under each coefficient of correlation.

\begin{tabular}{|c|c|c|c|c|}
\hline$\underline{\text { Trial }}$ & May 2007 & Sept. 2007 & Nov. 2007 & Feb. 2008 \\
\hline May 2006 & $\begin{array}{c}0.773 \\
(0.0001)\end{array}$ & $\begin{array}{c}0.261 \\
(0.0899)\end{array}$ & $\begin{array}{c}0.542 \\
(0.0098)\end{array}$ & $\begin{array}{c}0.223 \\
(0.1030)\end{array}$ \\
\hline May 2007 & - & $\begin{array}{c}0.468 \\
(0.0025)\end{array}$ & $\begin{array}{c}0.250 \\
(0.0577)\end{array}$ & $\begin{array}{c}0.262 \\
(0.0427)\end{array}$ \\
\hline Sept. 2007 & - & - & $\begin{array}{c}0.621 \\
(0.0003)\end{array}$ & $\begin{array}{l}0.450 \\
(0.0045)\end{array}$ \\
\hline Nov. 2007 & - & - & - & $\begin{array}{c}0.541 \\
(0.0008) \\
\end{array}$ \\
\hline
\end{tabular}

7,13 , and 19 July and 2 Aug., and for 2007, flowers were counted on 6, 14, 20 , and 26 June and 10 and 17 July.

\section{Results and discussion}

Fusarium wilt greenhouse trialsfusarium wilt was observed in all three greenhouse trials (Table 4 ). In the Sept. 2007 and Feb. 2008 trials, the first symptoms were observed $7 \mathrm{~d}$ postinoculation (data not shown). In the Nov. 2007 greenhouse trial, symptoms appeared $11 \mathrm{~d}$ postinoculation (data not shown). The disease severity in the 
Table 4. Susceptibility of diploid watermelon cultivars used as pollenizers for triploid watermelons to fusarium wilt in a greenhouse experiment conducted in Sept./Oct. 2007, Nov./Dec. 2007, and Feb. 2008.

\begin{tabular}{|c|c|c|c|}
\hline Cultivar $^{\mathrm{z}}$ & $\begin{array}{c}\text { Sept./Oct. } 2007 \\
\text { AUDPC }\end{array}$ & $\begin{array}{c}\text { Nov./Dec. } 2007 \\
\text { AUDPC }\end{array}$ & $\begin{array}{l}\text { Feb. } 2008 \\
\text { AUDPC }^{\mathrm{v}}\end{array}$ \\
\hline Ace & $470.5 \mathrm{a}^{\mathrm{u}}$ & $796.9 \mathrm{a}$ & $500.4 \mathrm{a}$ \\
\hline ACX 9825 & $439.0 \mathrm{a}$ & 898.9 a & $461.5 \mathrm{a}$ \\
\hline Allsweet & $201.7 \mathrm{~d}$ & $147.8 \mathrm{c}$ & $101.2 \mathrm{~cd}$ \\
\hline Black Diamond & $417.9 \mathrm{ab}$ & $805.4 \mathrm{a}$ & $442.1 \mathrm{ab}$ \\
\hline Companion & $146.7 \mathrm{de}$ & $558.6 \mathrm{~b}$ & $254.8 \mathrm{bc}$ \\
\hline Dixie Lee & $438.0 \mathrm{a}$ & $\mathrm{n} / \mathrm{t}^{\mathrm{t}}$ & $485.7 \mathrm{a}$ \\
\hline Jenny & $452.7 \mathrm{a}$ & 978.8 a & $368.1 \mathrm{ab}$ \\
\hline Mickey Lee & $236.6 \mathrm{~cd}$ & $517.2 \mathrm{~b}$ & $321.0 \mathrm{ab}$ \\
\hline Pinnacle & $417.4 \mathrm{ab}$ & $924.7 \mathrm{a}$ & $469.1 \mathrm{a}$ \\
\hline Polimax 6017 & $362.5 \mathrm{abc}$ & $840.3 \mathrm{a}$ & $435.8 \mathrm{ab}$ \\
\hline Regency & $\mathrm{n} / \mathrm{t}$ & $170.7 \mathrm{c}$ & $87.7 \mathrm{~cd}$ \\
\hline Royal Sweet & $\mathrm{n} / \mathrm{t}$ & $\mathrm{n} / \mathrm{t}$ & $336.6 \mathrm{ab}$ \\
\hline Sidekick & $216.0 \mathrm{~d}$ & $781.0 \mathrm{a}$ & $400.4 \mathrm{ab}$ \\
\hline SP-1 & $403.8 \mathrm{ab}$ & $920.2 \mathrm{a}$ & $468.2 \mathrm{a}$ \\
\hline SSC 2220 & $461.2 \mathrm{a}$ & $956.8 \mathrm{a}$ & $388.7 \mathrm{ab}$ \\
\hline SSC 2221 & $410.7 \mathrm{ab}$ & $888.0 \mathrm{a}$ & 467.7 a \\
\hline Tri-X Triple Threat & $378.9 \mathrm{abc}$ & $493.9 \mathrm{~b}$ & $322.3 \mathrm{ab}$ \\
\hline Tri-X 212 & $142.4 \mathrm{def}$ & $\mathrm{n} / \mathrm{t}$ & $\mathrm{n} / \mathrm{t}$ \\
\hline 5WDL 6132 & $0.0 \mathrm{f}$ & $70.7 \mathrm{c}$ & $21.6 \mathrm{~d}$ \\
\hline 5WDL 6146 & $1.8 \mathrm{f}$ & $43.8 \mathrm{c}$ & $\mathrm{n} / \mathrm{t}$ \\
\hline 5WDL 6148 & $15.8 \mathrm{ef}$ & $22.6 \mathrm{c}$ & $\mathrm{n} / \mathrm{t}$ \\
\hline$P$ value & 0.0001 & 0.001 & 0.0001 \\
\hline
\end{tabular}

${ }^{\mathrm{z}}$ Seeds were sown in a 4:1:1 mixture (v:v) of sand:peat:vermiculite and inoculated with $100 \mathrm{~mL}(3.38 \mathrm{fl} \mathrm{oz})$ of a $1 \times$ $10^{5}$ conidia/mL $\left(2.96 \times 10^{6}\right.$ conidia/fl oz $)$ suspension when the seedlings were at the first true-leaf stage. There were three seedlings per pot and each pot was replicated three times in a completely randomized design.

yThe area under the disease progress curve (AUDPC) was calculated from the Horsfall-Barratt ratings using trapezoidal integration (Shaner and Finney, 1977).

${ }^{x}$ Seedlings were rated on 25,27 , and 30 Sept. and 2 Oct. 2007.

wSeedlings were rated on 20,26, 28, and 30 Nov. and 3 Dec. 2007.

'Seedlings were rated on $8,10,12,14$, and 16 Feb. 2008.

"Means within each column with a letter in common are not significantly different via Fisher's protected least significant difference test at $P=0.05$.

tThe cultivar was not tested for that particular year.

Nov. 2007 greenhouse trial (Table 4) was about twice that in either of the other two trials (Table 4) based on the AUDPC calculated for the most susceptible cultivar in each greenhouse trial. However, the most differences between cultivars, as revealed by the multiple range tests, occurred in the Sept. 2007 trial (Table 4).

Susceptibility to fusarium wilt among the cultivars was relatively consistent between greenhouse tests. The correlations between the numerical rankings of cultivars in the greenhouse were $P=0.0045$ or less (Table 3 ). 'Black Diamond' did not differ from the most susceptible cultivar in each greenhouse test. The pollenizers 'Ace', 'Pinnacle', 'Jenny', and 'ACX 9825' were consistently among the most susceptible entries, while '5WDL 6148', '5WDL 6132', and '5WDL 6146' were among the most resistant pollenizer cultivars.

The greenhouse inoculation method used here is much quicker and less expensive than field trials. Data generated in this way can be used to help develop recommendations for commercial watermelon cultivars, including pollenizers, in areas where fusarium wilt is a limiting factor. In this study, even the lowest correlation between a greenhouse and a field test was $r^{2}=0.223[P=0.103$ (Table 3 ) , suggesting that all greenhouse tests had a fair degree of similarity to the fusarium wilt resistance that is observed in the field.

However, 'Dixie Lee' showed considerable resistance to fusarium wilt in our field studies (Table 2), but not as much in greenhouse tests in which it was included. Similarly, 'Royal Sweet' did not differ from the most resistant cultivar in both field trials (Table 2), while in 2008, greenhouse test was among the most susceptible cultivars.

FUSARIUM WILT FIELD TRIALS. Symptoms of fusarium wilt were first observed on 17 June 2006 and 1 June 2007. The most susceptible cultivar in each for the 2007 trial was more than four times that of the 2006 trial based on AUDPC (Table 2). Since the 2007 trial was planted in the same area as the 2006 trial, it is likely the increased disease pressure in 2007 was due in part to the crop residue and associated FON remaining from the 2006 planting. In addition, there was more precipitation in 2006 than in 2007, and this may have resulted in higher disease during 2007 since fusarium wilt symptoms are favored by relatively dry conditions (personal observations). There were more differences in fusarium wilt susceptibility between cultivars in field trials completed in 2007 than in 2006 (Table 2 ), which was likely due to the greater amount of disease present in 2007.

Although few differences were noted in the 2006 field trial, the correlation between the numerical rankings of cultivars used in both field trials was highly significant $[r=0.773$, $P=0.0001$ (Table 3)]. The diploid 'Black Diamond' was either the most susceptible to fusarium wilt or did not significantly differ from the most susceptible cultivars in both field trials (Table 2). This was expected since 'Black Diamond' was included because of its high degree of susceptibility to fusarium wilt (Martyn, 1987; Martyn and McLaughlin, 1983). The diploid 'Dixie Lee' was included in the trials because of its relative resistance (Martyn, 1987; Martyn and McLaughlin, 1983), and it was not different from the most resistant cultivars in both field trials. Among the diploid pollenizer cultivars that appeared in both trials, ACX 9825, Pinnacle, and Polymax 6017 were among the most susceptible, while 5WDL 6146 and Companion were the most resistant.

Staminate Flower COUNT IN FIELD TRIALS. Cultivars differed from each other in staminate flower counts in both 2006 (Fig. 1) and 2007 (Fig. 2 ); however, there were fewer differences between cultivars in 2006 than in 2007. In both years, ' $5 \mathrm{WDL}$ 6146', 'SP-1', and 'Sidekick' had higher staminate flower counts than most of the other cultivars. This high staminate flower count was also observed by previous researchers in 'SP-1' and 'Sidekick' (Dittmar et al., 2009; Freeman and Olson, 2007; Freeman et al., 2007). They observed that both of these cultivars exhibited substantial multibranching in their 


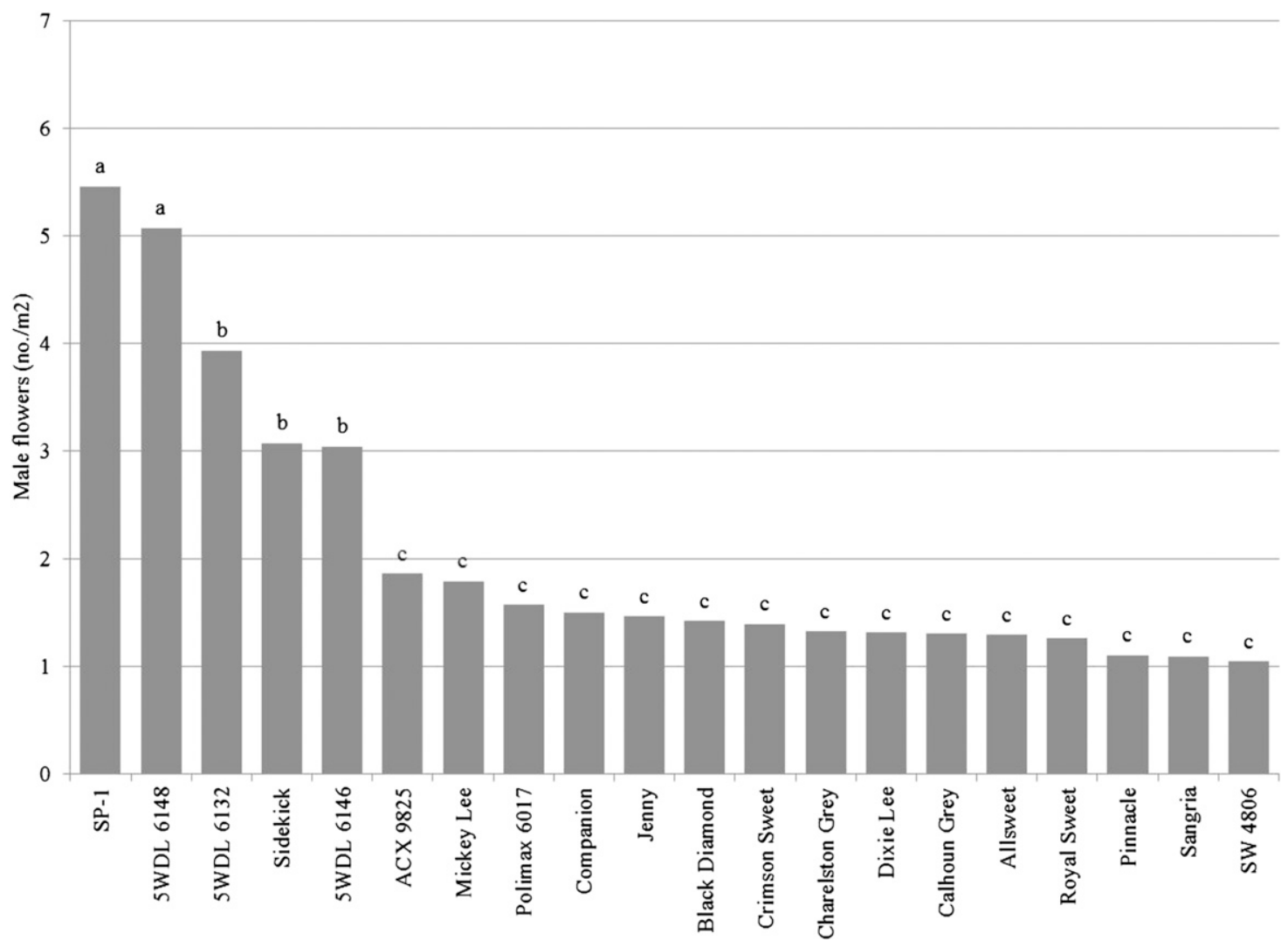

Fig. 1. Mean number of staminate flower of nonharvested watermelon pollenizers in the 2006 field trials. The trials were conducted in a commercial watermelon field in May 2006; 1 flower $/ \mathrm{m}^{2}=0.0929 \mathrm{flower} / \mathrm{ft}^{2}$.

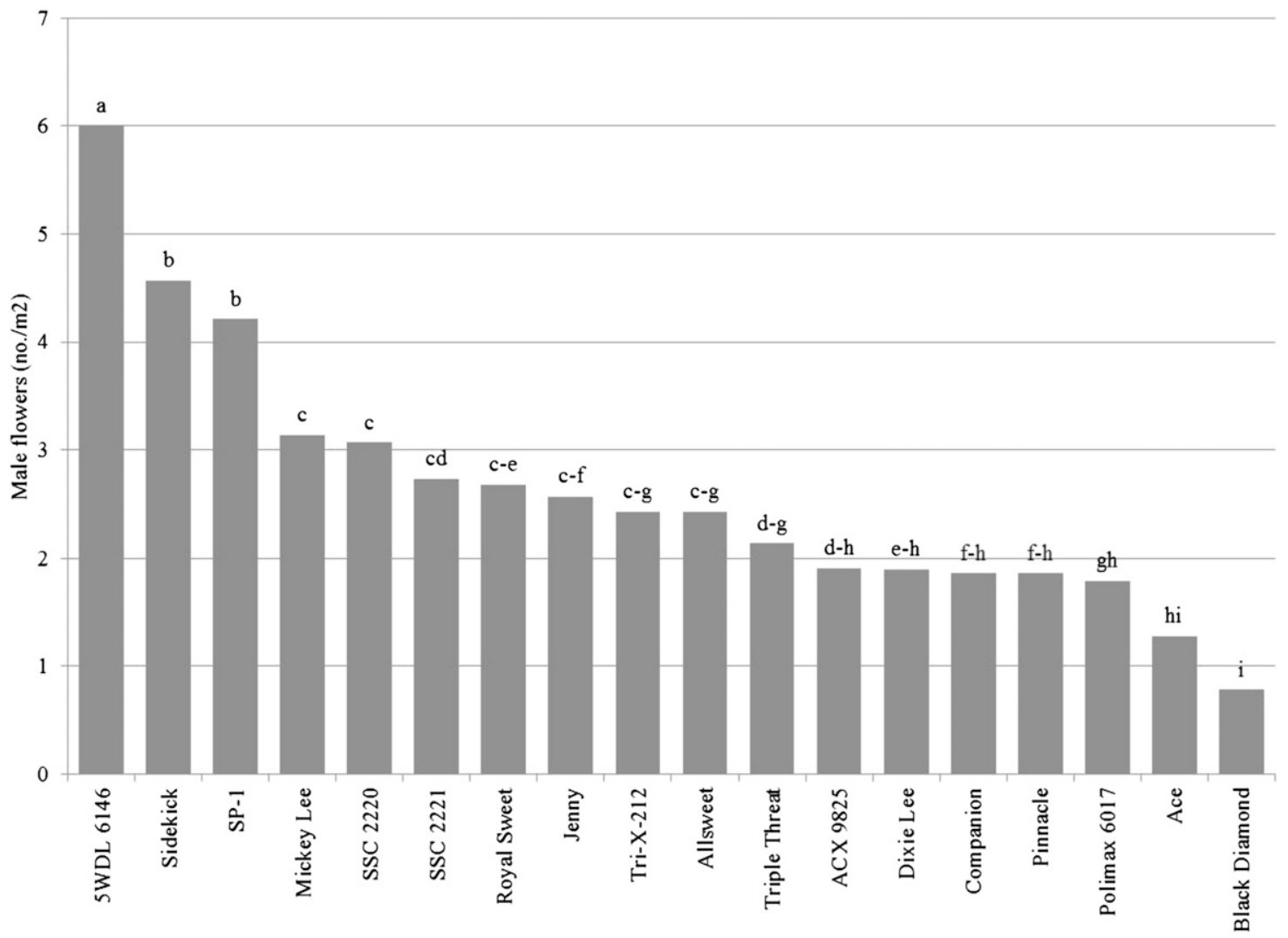

Fig. 2. Mean number of staminate from nonharvested watermelon pollenizers in the 2007 field trials. The trials were conducted in a commercial watermelon field in May 2007; 1 flower $/ \mathrm{m}^{2}=0.0929 \mathrm{flower} / \mathrm{ft}^{2}$. 
growth habit and the increased number of nodes is a likely explanation for the increased flower number. In both years, 'Mickey Lee' had significantly lower flower numbers than the cultivars just mentioned (Figs. 1 and 2). However, among the remaining cultivars in both years, Mickey Lee had numerically higher flower numbers. 'Mickey Lee' had moderate resistance in the greenhouse and field tests (Tables 2 and 4 ) and is relatively inexpensive compared with specialized pollenizers.

It is interesting to note the similarities in the fusarium wilt severity data from the 2006 and 2007 field seasons and the staminate flower count data from the same periods. In 2007, 'Ace', 'Pinnacle', and 'Black Diamond' had low flower counts and similarly high levels of fusarium wilt (Table 2 and Fig. 2). In the same year, '5WDL 6146' and 'Sidekick' had relatively low fusarium wilt severity and high staminate flower counts. More differences were observed in the fusarium wilt severity data and the staminate flower counts in 2006 than in 2007. 'Pinnacle' had low staminate flower counts and high fusarium wilt in that year, while the '5WDL 6148' had low fusarium wilt severity and high staminate flower counts. However, not all cultivars followed this trend as Royal Sweet had both low levels of fusarium wilt severity and staminate flower counts in 2007. 'Royal Sweet' is a cultivar that was not bred for use as a nonharvested pollenizer. It appears that the development of staminate flowers and the severity of fusarium wilt severity are not correlated. However, it should be noted that increased fusarium wilt severity can result in lower numbers of plants surviving to produce staminate flowers, depending upon when during the crop development cycle that disease occurs.

The information on staminate flower counts and fusarium wilt reactions may help watermelon growers to select nonharvested pollenizer cultivars for use in triploid production. As new cultivars of nonharvested pollenizers become available, greenhouse assays of the type used in this study may also help differentiate fusarium wilt reactions in those cultivars.

The difference in staminate flower production among diploid watermelon cultivars is known (Dittmar et al., 2009, 2010; Fiacchino and Walters, 2003; Maynard and Elmstrom, 1992; Rhodes et al., 1997). This study quantifies staminate flower production in diploid cultivars in a commercial field with a known history of fusarium wilt. In addition, symptoms of fusarium wilt on seedlings of diploid watermelon cultivars are examined in greenhouse tests. The use of this data to choose appropriately resistant diploid pollenizers may help to maximize staminate flower production and therefore triploid watermelon fruit production.

\section{Literature cited}

Dittmar, P.J., D.W. Monks, and J.R. Schultheis. 2009. Maximum potential vegetative and floral production and fruit characteristics of watermelon pollenizers. HortScience 44:59-63.

Dittmar, P.J., D.W. Monks, and J.R. Schultheis. 2010. Use of commercially available pollenizers for optimizing triploid watermelon production. HortScience 45:54l-545.

Egel, D.S., R. Harikrishnan, and R. Martyn. 2005. First report of Fusarium oxysporum $\mathrm{f}$. sp. niveum race 2 as causal agent of fusarium wilt of watermelon, in Indiana. Plant Dis. 89:108.

Egel, D.S. and S. Hoke. 2007. Evaluation of triploid watermelon for resistance to fusarium wilt, 2006. Plant Dis. Mgt. Rpt. 2:V020, doi: 10.1094/PDMR01.

Egel, D.S., W.K.F. Lam, R. Foster, and E. Maynard. 2006. Midwest vegetable production guide for commercial growers Coop. Ext. Serv., Purdue Univ. ID-56.

Egel, D.S. and R.D. Martyn. 2007. Fusarium wilt of watermelon and other cucurbits. Plant Health Instructor, doi: 10.1094/PHI-I-2007-0122-01

Elmstrom, G.W. and D.L. Hopkins 1981. Resistance of watermelon cultivars to fusarium wilt. Plant Dis. 65:825-827.

Esposito, R. and A. Fletcher. 1961. The relationship of pteridine biosynthesis to the action of copper 8-hydroxy-quinolate on fungal spores. Arch. Biochem. Biophys. 93:369-376

Fiacchino, D.C. and S.A. Walters. 2003. Influence of diploid pollenizer frequen cies on triploid watermelon quality and yields. HortTechnology 13:58-61.

Freeman, J.H., G.A. Miller, S.M. Olson, and W.M. Stall. 2007. Diploid watermelon pollenizer cultivars exhibit varying degrees of performance with respect to triploid watermelon yield. HortTechnology 17:518-522.

Freeman, J.H. and S.M. Olson. 2007 Characteristics of watermelon pollenizer cultivars for use in triploid production. Intl. J. Veg. Sci. 13:73-80.

Horsfall, J.G. and R.W. Barratt. 1945. An improved grading system for measuring plant diseases. Phytopathology 35:655. (abstr.).

Kleczewski, N.M. and D.S. Egel. 2011. A diagnostic guide for fusarium wilt of watermelon. Plant Health Prog., doi: 10.1094/PHP-2011-1129-01-DG.

Lucier, G. and B.H. Lin. 2001. Vegetables and specialties situation yearbook. Econ. Res. Serv. U.S. Dept. Agr., Washington, DC.

Martyn, R.D. 1987. Fusarium oxysporum f. sp. niveum race 2 : A highly aggressive race new to the United States. Plant Dis. 71:233-236.

Martyn, R.D. and R.J. McLaughlin. 1983. Effects of inoculum concentration on the apparent resisitance of watermelons to Fusarium oxysporum f. sp. niveum. Plant Dis. 67:493-495.

Maynard, D.N. and G.W. Elmstrom. 1992. Triploid watermelon production practices and cultivars. Acta Hort. 318:169:173.

Nesmith, S. and J. Duval. 2001. Fruit set of triploid watermelon as a function of distance from a diploid pollenizer. HortScience 36:60-61.

Rhodes, B., K.B. Gruene, and W.M. Hood. 1997. Honey bees waste time on triploid flowers. Cucurbit Genet. Coop. Rpt. 20:45.

Shaner, G. and R.E. Finney. 1977. The effect of nitrogen fertilization on the expression of slow-mildewing resistance in Knox wheat. Phytopathology 67:1051-1056.

Stanghellini, M.S., J.T. Ambrose, and J.R. Schultheis. 1998. Seed production in watermelon: A comparison between two commercially available pollinators. HortScience 33:28-30.

Stanghellini, M.S. and J.R. Schultheis. 2005. Genotypic variability in staminate flower and pollen grain production of diploid watermelons. HortScience 40:752-755.

U.S. Department of Agriculture. 2003. Vegetables and melons outlook. U.S. Dept. Agr., Econ. Res. Serv. VGS-296.

Zhang, X.W., D.L. Jiao, L. Na, X.S. Huang, and Q.S. Gu. 1995. A preliminary report on screening the resistance of watermelon cultivars to fusarium wilt. Acta Hort. 402:45-47.

Zhou, X.G. and K.L. Everts. 2004. Quantification of root and stem colonization of watermelon by Fusarium oxysporum f. sp. niveum and its use in evaluating resistance. Phytopathology 94:832-841. 